\title{
"We're not murderers. We just survive."1
}

\author{
The Ideological Function of Game Mechanics in
}

\section{Zombie Games}

\section{Eugen Pfister}

In 2019, Ubisoft lead developer Sébastien Le Prestre said in an interview with Gamespot: "We're creating a game here, we're not trying to make political statements in our games. We've rooted ourselves in reality, and you'll get what you get out of your playthrough - everybody will get something different out of their experience. The story might make you see different situations, but we're not trying to guide anybody or to make any sorts of statements." (Webster 2019) Contrary to such claims from the video game industry, digital games cannot be thought of as operating separately from society and its politics. Games emerge out of society and inevitably carry statements of social and political discourses within them: "The stories we tell reflect our understanding of the world and the society in which we live, even if such tales appear firmly rooted in the fantastic." (Barr 2020: 28) Games play with our hopes and fears. They reproduce - consciously and subconsciously - distinct ideas of the world and convey values whenever they construct ideas of good and evil, for example. In games, we encounter brave warriors and corrupt politicians; we fight for freedom and against oppression. In terms of historical discourse analysis, we can therefore speak of dominant ideological statements that are communicated and constructed.

How, then, can we recognize and analyze these dominant statements? Of course, the most obvious way is to spot them in the narrative running through the games: Is there a central conflict? What are the causes of this conflict? Who are the heroes? Who are the enemies? To this end we can take inspiration from media studies, or more generally from the social sciences, where phenomena such

1 Quote from the character Ellie in The Last of Us. 
as political socialization and cultivation in mass media have been studied for quite some time. Studies in these fields have shown us that many narrative traditions in digital games - rhetoric methods, for instance (Schrape 2012: 12-16) have been heavily inspired by novels, films and television series (Krzywinska 2009: 271; Kirkland 2009: 62-65; Schrape: 60). At the same time we know that a focus on the narrative level alone is not enough to reveal their dominant ideological statements, because digital games are more than just another new narrative medium, they are also an interactive experience, and, at the same time, a computer program (Schrape: 88). Thus, games not only communicate ideas through a series of meaningful events strung together in a story, but potentially allow for the emergence of many - possibly contradictory - ideas within their game rules.

Therefore the question is opportune as to whether we can investigate ideology transfers in games at all. Delimited by the framework of their code, the individual act of playing them not only creates a narrative, but within this framework lies the potential for an infinite number of different narratives. We can play games aggressively or defensively, curiously or carefully. We can try to live up to our morals in the game or, on the contrary, decide to deliberately try the opposite. What does this mean for research? Does the fact that not only is each game potentially different from every other but also every playthrough of the same game, mean that we are no longer dealing with just one narrative, but an infinite number? Does this mean that each game contains not just one set of political ideas but potentially an infinite number of contradictory ones? In the following text I would like to demonstrate, using a sample of games with zombie settings, that this is not the case.

Meaning is not only produced in games via narrative and audiovisual aesthetics, but also by game mechanics. The rules, set by the developers, raise challenges, offer opportunities for actions and evaluate the players. "To evaluate is to reward or punish, to give a positive or negative feedback" (Suter 2018: 22). Game mechanics cannot therefore be free of judgement, because they themselves judge the players. They are interwoven with the narrative and the aesthetic design (Kirkland 2009: 63). Together they form a ludonarrative (Aarseth 2012), with the result that since the vast majority of players have such similar experiences, we can speak of dominant discursive statements. Adam Chapman has used the concept of affordances to tackle a similar phenomenon where certain guidelines as to how the game should be played are embedded in the game mechanics. (Chapman 2016: 173; Schrape 2012: 76) Until now, political content in digital games has been sought - I am also referring to myself here - primarily in the story and the characters. This is due to reliance on other forms of media studies, which have, as their research topics, more traditional forms of media. The pecu- 
liarity of digital games, I would argue, requires an additional research focus on the gameplay elements, i.e. the rules and mechanics of the game. For it is also through these that ideological statements are transported in games. Therefore we can assume that all players, adhering to the game rules, encounter the same ideas. Of course, there will always be some exceptions, for example, when players deliberately play against expectation, such as in pacifist runs. But for the vast majority of players from the same cultural background, the gaming experience will be so similar that it is possible to form general assertions concerning political statements. In the following I would therefore like to show that the rules of the game (in the sense of a language) also obey discursive rules. To this end, I will examine dominant statements on the one hand, but will also search specifically for counterstatements. The latter show particularly impressively that certain elements of the game perceived as "natural" are in reality only due to discursive traditions. To demonstrate this, I will focus on some specific gameplay elements from zombie games, since these games lend themselves particularly well to such an analysis: despite their ubiquity, they all share a similar design (and narrative) and interact strongly with current political debates. (Pfister 2020b)

It is important to keep in mind that digital games - like popular culture in general - are not just an image or mirror that can be held up to society. From the understanding of historical discourse analysis, they actively construct our social reality too. (Landwehr 2009: 17; Sarasin 2003: 12) In other words: we also learn about the world we live in by playing digital games, and to an extent we are also socialized by them. (Klimmt 2009: 68) The values communicated in digital games are thus not only a product of the society that creates them, but they also actively shape that society. In our increasingly hypercomplex society, popular culture functions as a communicative space for binding common values and world views. Examples of this include public opinion on military operations abroad or questions surrounding the legitimacy of torture. If political power increases in relation to it not being questioned, then the importance of a negotiation of values through popular culture becomes apparent. The more often something (a political problem or constellation) is confirmed for us in the media, the less inclined we are to question it. Thus it seems plausible ex negativo that, for example, an increasing fear of democratic failure or the loss of trust in political figures and institutions in popular culture is not only a mirror of a "real" political development, but also contributes to it. This way of thinking becomes "naturalized". In other words: the more often we encounter incapable/corrupt/amoral politicians in film and television, the more we are inclined to also attribute this image to "real" politicians. Conversely, this would mean that a regular repetition 
of the "strong man" politician can also lead to a normalization of this topos (Pfister 2020a).

\section{POLITICS IN HORROR GAMES}

For my ongoing research project, I have therefore been studying the construction and communication of political ideas in popular culture, concentrating mainly on horror games. The horror genre in movies and novels traditionally helps reaffirm the outer borders of our collective identities by focusing on taboos and the abject (Santilli 2007), both aspects of which are central to the figure of the zombie. So the question to ask is whether this is also transferable to games, and if so, what role do game mechanics play? By analyzing zombie games as an additional source for a contemporary history of political ideas, we can better understand contemporary discourses on democracy, society and ethics. According to John S. Nelson, horror functions as a primer for political action: “Awaken to evils in our midst. Turn to face those shadows, revealing awful forms more human than we had imagined. Unite to track down those troubles, confronting them at home" (Nelson 2005: 382). In Nelson's logic, this call to action happens via subtext: "(S)ymbolism that creeps beneath surface meanings to assault and awaken our minds" (ibid: 382). According to Lauro (2011: 128) the figure of the zombie first and foremost serves as a narrative of crisis and threat. While this is also true for the zombie figure in games, it does not mean that all zombie games transport the same statements. In another essay I showed that in terms of their function, zombie stories can be understood in a certain way like a language. They provide a syntax and grammar, but do not fully determine the message. In the past, zombie films, novels and games therefore treated critical topics as diverse as racism, consumerism and libertarianism (Rath 2014).

We may assume that the ideological statements inherent in the figure of the zombie are also known to most game developers. In an essay about zombies and game mechanics, game designer Christopher Totten discusses the allegorical implications of the zombie figure in an entire paragraph, describing zombies as embodiment of our societal fears (Totten 2012). In his interviews held with game developers of zombie games, Matthew Barr discovered that they were well aware that their games "tap into contemporary fears" (Barr 2020: 28). This does not mean, however, that all ideological statements in games are deliberate. It lies in the nature of the discourse as a disembodied system of dominant ideas and rules of what we can say and what we can think, that the system reproduces itself in our culture, even if we are unaware of the fact (Pfister 2018). In concrete 
terms, this means that, in most cases, narratives and game mechanics have simply been unconsciously adopted by the developers. Even those game developers that choose zombies as a 'narrative convenience', or to disguise the poor artificial intelligence of non-player characters (Perron 2020: 198), are reproducing dominant discursive statements via the narrative, aesthetics and game mechanics.

In general, it is impossible to make a distinction between narrative, aesthetics and game mechanics in digital games, as the boundaries are fluid. The (ostensible) methodological dispute between ludologists and narratologists in the early 2000s had as its only conceivable outcome a synthesis of the two methodological approaches: "What has so far been lacking is a detailed, robust understanding of the various ways computer software have been used to combine elements from narratives and games into a number of quite different ludo-narratological constructs" (Aarseth 2012). Just as the story determines the rules of the game (War, Survival, etc.), the graphic design is an intrinsic part of the created game world just as much as the game mechanics (First-Person Shooter, Horror-Survival, etc.) determine the story. Henry Jenkins, for example, speaks of an "embedded narrative" (Kirkland 2009: 70) and thus concentrates on the level design and aesthetics of games. Ian Bogost in turn created the term "procedural rhetoric" to describe the rhetoric of games, where arguments are made "through the authorship of rules of behaviour, the construction of dynamic models." (cited in Weise 2015: 239) Since, in the past, political content in games has often been examined based on the story, I would like to concentrate here on the rules and gameplay of the game, despite the impossibility of making a clear-cut distinction, for the sole purpose of demonstrating its importance. Since it is not possible for me to list here all the game mechanical aspects of all zombie games, I will concentrate on those that I have noticed as dominant moments in my research so far.

\section{THE CONFLICT PARADIGM}

First of all, there is the paradigm of constant conflict embedded in the program. Of course, this is also connected with the fact that at the moment at least, the vast majority of all digital games are still based on conflict or competition mechanisms. No matter whether we are playing within a small team to deal with overwhelming hordes such as in Left4Dead, or on our own sneaking past the 'infected' in the Last of Us. Whether we are engaged in a First- or Third-Person Shooter, whether playing a twin-stick shooter or strategy game, as players we commonly have only one choice: kill the zombies or be killed by them (Jorgensen 2020: 133; Perron 2020: 197). At first glance, this seems to be self-evident: 
If we are attacked in a zombie setting, we have to defend ourselves. Yet a brief look at other media shows that this approach is by no means self-evident. Films such as Shaun of the Dead, Warm Bodies and The Girl with all the Gifts and series like iZombie have shown that zombie films do not necessarily have to focus on combat alone. But counterexamples can also be seen in digital games. The very successful The Walking Dead games by Telltale are not entirely without fighting scenes. They do, however, focus much more on interpersonal relationships, which is a core element of the zombie narrative in other media. These examples show us that combat is not a natural prerequisite for all zombie settings in digital games.

On the contrary, a focus on fighting can even lead to moments of ludonarrative dissonance, which we can see in the extremely successful The Last of Us games. Both games rely very heavily on a well-written story and strong characters but suffer from an inherent contradiction between story and game mechanics. In the second part in particular, the extremely explicit depictions of violence between human survivors is intended to make the players think about the actions of the protagonist. But this introspection is never granted to all the NPCs killed during normal gameplay. This contradiction is a particularly challenging moment for academic research. On the one hand, we read in interviews that the game was meant as a critique of violence. At the same time, the game mechanics between the narrative cutscenes force us to repeat violent actions and - what is more important - without question. Since the routine killing of NPC goes unquestioned, but at the same time we are not usually offered alternative solutions, it is justified in the game by the rules.

This question is not trivial, quite the opposite. Interviews show that in many cases zombies were explicitly chosen as opponents for the reason of avoiding possible ethical questions. (Barr 2020: 19) At the same time, unlike aliens, demons and robots, zombies are especially frightening exactly because they are so human. So in a way, these games teach us to put aside the ethical concerns that we develop, for example, in the context of cutscenes, during gameplay. The focus on armed conflict may thus initially have been due to the limitations of the medium (Taylor 2009: 51), but is, above all, a culturally established tradition that severely restricts the ideological statements of the games in the sense of an assumed natural state of infinite conflict. (Pfister 2020b) 


\section{HUMAN NPCS}

Every zombie was once human. But while other media use precisely this aspect as a narrative moment, the transformation from human to undead in games usually happens immediately and unobserved - with the exception of Telltale's The Walking Dead. Zombies may have been human, but now they are the others, the threat - a textbook example of "othering": "Unfortunately, video games have few instances of terror-inducing explanations for their zombies. There is rarely time to explore how someone was zombified; the outbreak has already filled the screen with zombies. Often, these monsters are either character models with no memorable features or are twisted mutations no longer resembling humans." (Totten 2012) In the games we do not even have time to ask ourselves what kind of people they might have been, be they waitresses or lawyers, grandfathers or criminals. We usually only have three forms of interaction at our disposal: fight, hide-and-seek, or flee. One could argue here that this is due to technical restrictions. Fights are easier to program than open-ended interpersonal relationships. In view of complex game worlds in series such as Mass Effect, Pillars of Eternity and The Witcher 3, however, this argument is increasingly losing its persuasive power. This would mean that the mechanics of the game here primarily follow discursive rules of the sayable and showable. This also raises the question of why, for example, the search for a cure almost never becomes a game objective. Even more serious than the unquestioned conflict paradigm itself is the fact that, following genre conventions, in many games it is not the zombies that are the real antagonists but people.

Particularly interesting for us are therefore those games that show that other paths can be taken in terms of game mechanics. A case in point is the Dead Rising game series, which is based on a constant fight against zombies, but extends it, for example, with rescue missions in which other survivors have to be protected from zombies. In State of Decay 2, players have the opportunity to expand their own base. In addition, they can administer remedies to victims of the socalled "Blood Plague" in their infirmary. These last two examples - as well as the two smaller game projects Atom Zombie Smasher and They Are Billions - in particular show that zombie narratives in themselves can offer more scope for diversified game mechanics than most previous zombie games would have us believe. This was demonstrated not least by Telltale's very linear narrativeheavy adaptation of The Walking Dead, which enjoyed more success in comparison to Overkill's classic FPS adaptations of The Walking Dead. The lack of possible meaningful interactions with human NPCs in most games may originally have been due to technical restrictions, but it is still not free of ideology. This is 
because there is a strong resonance between the narrative and audiovisual aesthetics of games, both of which also emphasize the isolation of the individual.

\section{SINGLE-PLAYER VS. MULTIPLAYER}

An examination of the differences between single- and multiplayer games is also enlightening, as interpersonal dynamics potentially cancel out the statements of narrative settings. Narrative games like The Last of Us, but also Days Gone and Dying Light paint a particularly gloomy picture of human nature post-zombie apocalypse. Not only have our democratic structures and social order collapsed locally or globally in the blink of an eye, there appears to be something even worse than the zombies: a battle of everyone against everyone else. (Pfister 2020b) People have been thrown back to an apparent primordial state of perpetual war for survival where, much more than the zombies, the other survivors are the enemy. The fascist military regime and its goons in The Last of Us, murdering psychopaths in Dead Rising and a gang of cultists in Days Gone, to name a few examples. In classic single-player campaigns, this means that the players are on their own and can only rely on their own abilities and moral decisions. The ethical choices of characters inevitably become our own. In exceptional cases they even are embedded game mechanics, as shown by the moral choices in Telltale's The Walking Dead (Barr 2020: 17) or The Organ Trail. This does not mean that we unquestionably adopt the political convictions presented here, but for the time of the play we have to identify with the character without being able to exert real influence most of the time, just as in a film. That means we have to accept the rules of the game world to find our way through it: "The most productive gameplay strategy involves correctly reading these grammatical and visual cues, completing the actions being foreshadowed [...]" (Kirkland 2009: 69). We learn from the beginning to mistrust human NPCs we meet in the game world, and we do not expect help from other survivors. Thus many zombie games communicate a worldview of a (neo-)liberal individualism: What emerges is the myth of the lone hero as the epitome of the individual, who alone is capable of making ethical decisions. This should be of no surprise to us as it simply corresponds with the current dominant political climate in line with the neoliberal paradigm, confirming my earlier statement that myths are always a contemporary phenomenon. As Zygmunt Bauman shows in his book Liquid Modernity, individualization is fate and not choice in the neoliberal state (Baumann 2001: 69). According to Bruno Amable, neoliberals have realized that in order for their 
ideology to be successful, a state's populace must internalize the belief that individuals are only to be rewarded based on their personal effort. (Amable 2011: 5)

But while single-player campaigns, both in narrative and in game mechanics, elevate the individual to the last moral authority, the opposite happens in multiplayer campaigns, not least through the cooperation of several human players. My personal first multiplayer experience in a zombie game was the Couch CoOp mode of Left4Dead. Here, the personal bond with the other player(s) makes cooperation the dominant game principle. So in this instance - due to the different game situations - there are contrary ideological statements. The survivors are dependent on each other. This is true for most co-op games and naturally increases when the players know each other. However, the degree of cooperation is mainly based on existing social interactions. One feels closer to a friend or family member at home and therefore more committed than to anonymous players on the net. In multiplayer arenas like DayZ there are again other forms of social interaction. In these arenas, beginners - "noobs" have to beware of "trolls" and "griefers" - in a similar way to many other multiplayer arenas. At the same time, spontaneous social groups - especially clans based on close cooperation are emerging.

\section{A GAME OF SCARCITY}

Another aspect many zombie games have in common is that they depict a world of scarcity: a lack of weapons, ammunition, and a general lack of resources (Therrien 2009: 37; Fawcett \& McGreevy 2020: 86). Especially in a world of abundance this is a potent symbol. One reason for this theme is, of course, the attempt to maintain the game's balance and keep it exciting. This shortage makes the management of resources a game-determining moment. Players have to weigh up exactly when to use which weapon. In some games such as Dead Island and State of Decay, not only is the ammunition sparse, but the melee weapons themselves are exhausted over time. This mechanism teaches players to use resources sparingly, sometimes almost over-cautiously, for fear of finding themselves defenseless in major confrontations. Here, too, zombie games use the myths of nature as challenging, as well as depicting it as a simpler state of being, in the tradition of Robinson Crusoe. The focus on inventory management was introduced with Alone of the Dark (Barton 2020). However, it also resonates well with horror in other media in that the protagonist is introduced as a vulnerable subject. The absence of cultural resources gives the impression of a natural state of scarcity. Against the background of the "prepper" phenomenon, which is cur- 
rently spreading in society, there is also a strong ideological resonance. This game mechanism also works so effectively because it serves an increasingly widespread fear of the collapse of our commodity chains.

\section{ACHIEVEMENT HUNT}

Achievements and trophies in digital games, i.e. rewards given by the program, is a topic still somewhat neglected by game studies. Basically, three different forms of rewards can be identified:

1. rewards for normal progress in the game,

2. rewards for particularly intensive and complete exploration of the game, and

3. rewards for extravagant or counterintuitive actions in the game.

These achievements and trophies "nudge" the players - which is especially true for so-called completionists, i.e. a player who feels the need to complete 100 per cent of the gameplay. In Dead Rising, a player receives one achievement for killing 1000, 10.000 and 53.594 zombies, called "Zombie Hunter", "Zombie Killer" and "Zombie Genocider" respectively. Incidentally, Left4Dead also had a "Zombie Genocider" achievement for killing 53.595 zombies in the game, in direct reference to Dead Rising. In Dead Island, 18 out of 54 achievements are centered on killing zombies or humans. "Kill 50 zombies using a vehicle" is the instruction for the achievement "Karma-Geddon". In addition to the number of enemies killed, some games also reward concrete scenarios. In Dying Light, for example, the achievement "BBQ" can be found. Here you have to stake a lighted zombie on a skewer.

At the same time, an increasingly visible effort is being made on the part of the developers to not only reward the killing of zombies, but also other behavior. The trophy "I want to talk about it" rewards players for engaging in all optional conversations in the game The Last of Us. Days Gone awards trophies for rescuing NPCs and gaining the trust of NPC encampments. Left4Dead rewards players for rescuing their co-op partners. These rewards are of special interest to us because they reveal the developers' intentions: What behavior do they want to reward players for? 


\section{POLITICAL TRANSFERS IN ZOMBIE GAMES}

It was not possible for me within the scope of this article to reflect in detail on all game mechanical aspects at work in zombie games, and their ideological implications. For example, an analysis of the horde-mechanic would also have been interesting: What most zombie games have in common is that individual zombies are harmless and they build up their threat mainly through their sheer mass and by advancing in unmanageable waves. Possible ideological transfers here are apparent (Barr 2020: 19). It was not my intention to produce an exhaustive overview of all possible transfers of ideology via game mechanics, but to throw a first spotlight onto this phenomenon through some specific examples. Thus I was hopefully able to show that the majority of zombie games use game rules that convey a world of constant conflict, of scarcity, in which we can only rely on ourselves. In order to master these games we internalize these experiences and act accordingly in the game (Pinchbeck 2009: 82). However, if we want to understand the ideological statements in games in their entirety, such an analysis can only be done in conjunction with an equally intensive analysis of the narrative and audiovisual aesthetics, as I mentioned before. I am convinced that meaningful political statements - and potential ideological transfers - only emerge when these three levels interact. In that case, we combine the learned behavior in the game - i.e., for example, our reaction to a threat - with meaning, which we derive from the narrative. When we walk through the ruins of cities and government districts in games, when we learn in the story that we can no longer rely on the military, and when we are left on our own in a gameplay of constant threat and combat we learn from constant repetition in different games, but also in other media, to increasingly accept the plausibility of an overwhelmmed democratic system no longer capable of guaranteeing our safety (Pfister 2020b).

The same can be said for the "othering" of groups of people who are perceived as a threat to us. In games, the others - i.e. the zombies - are dehumanized aesthetically in order to be acceptable as enemies. In a previous essay, I showed how mutual influences can be seen in a comparison of zombie games and the coverage of the so-called 'refugee crisis' in the yellow press. I do not want to insinuate that there was a direct influence of zombie narratives on the media coverage; there are, however, very strong similarities in the narration and argumentation but also in the audiovisual staging, which speaks for unconscious transfer processes. Dominant discursive statements - beware of the horde of "others", overburdened democratic systems, etc. - were used, that were already 
widespread. These are not only applied in a fictional framework but also in our everyday world. (Pfister 2020a)

Above all, my central concern was to show that game mechanics themselves cannot be value-free. "Computer programs, like all texts, will always be ideological constructions." (Friedman 1995). Zombie games are not only harmless fun, they are artifacts of our culture. And as such they obey the rules of discourse. When they tell us to rely only on our own judgement, this is of course due to a perceived need to strengthen the perceived agency of the players. But counterexamples of cooperative play and new narratives of cooperation show that this game mechanic is in no way a "natural" prerequisite of video games.

All of this should not lead us to a culturally pessimistic rejection of games, because games also grow and change with our society. Therefore it was important for me to present counterexamples for all dominant statements. Games that reward cooperation between players are evidence of this. Finally, the relevant question from both a historical and a day-to-day political point of view is therefore whether new dominant discursive statements will be formed from these game mechanical building blocks in the future.

\section{REFERENCES}

\section{Literature}

Aarseth, Espen (2012): “A Narrative Theory of Games.” In: Foundations of Digital Games Conference Proceedings, pp. 129-133.

Amable, Bruno (2011): „Morals and politics in the ideology of neo-liberalism.“ In: Socio-Economic Review 9, pp. 3-30.

Barr, Matthew (2020): "Zombies Again? A Qualitative Analysis of the Zombie Antagonist's Appeal in Game Design". In: Stephen Webley/Peter Zackariasson (eds.), The Playful Undead and Video Games Critical Analyses of Zombies and Gameplay, London: Routledge, pp. 15-29.

Barton, Matthew (2020): "Resurrecting 'Obsolete' Video Game Techniques from Alone in the Dark." In: Stephen Webley/Peter Zackariasson (eds.), The Playful Undead and Video Games Critical Analyses of Zombies and Gameplay, London: Routledge, pp. 30-43.

Bauman, Zygmunt (2001): Liquid Modernity, Cambridge: Polity Press.

Chapman, Adam (2016): Digital Games as History: How Videogames Represent the Past and Offer Access to Historical Practice, London: Routledge. 
Fawcett, Christina/McGreevy, Alan (2020): "Resident Evil and Infectious Fear." In: Stephen Webley/Peter Zackariasson (eds.), The Playful Undead and Video Games Critical Analyses of Zombies and Gameplay, London: Routledge, pp. 85-98.

Friedman, Ted (1995): "Making Sense of Software: Computer Games and Interactive Textuality." In: Steve Jones (ed.), Community in Cyberspace, Thousand Oaks: Sage.

Jorgensen, Kristine (2020): "Dead Rising and the Gameworld Zombie". In: Stephen Webley/Peter Zackariasson (eds.), The Playful Undead and Video Games Critical Analyses of Zombies and Gameplay, London: Routledge, pp. 126-137.

Kirkland, Ewan (2009): "Storytelling in Horror Video Games.” In: Bernard Perron (ed.), Horror Video Game, Jefferson: McFarland. pp. 62-78.

Klimmt, Christoph (2009): "Empirische Medienforschung: Kommunikationswissenschaftliche Perspektiven auf Computerspiele." In: Tobias Bevc/Holger Zapf (eds.), Wie wir spielen was wir werden. Computerspiele in unserer Gesellschaft. Konstanz: UVK, pp. 65-74.

Krzywinska, Tanya (2009): "Reanimating H.P. Lovecraft: The Ludic Paradox of Cthulhu: Dark Corners of the Earth.” In: Bernard Perron (ed.), Horror Video Game, Jefferson: McFarland. pp. 267-288.

Landwehr, Achim (2009): Historische Diskursanalyse, Frankfurt am Main.

Lauro, S. J. (2011): The Modern Zombie: Living Death in the Technological Age, Ph.D. Thesis, University of California.

Nelson, John S. (2005): "Horror Films Face Political Evils in Everyday Life." In: Political Communication 22/3, pp. 381-386.

Perron, Bernard (2020): "The Pace and Reach of Video Game Zombies." In: Stephen Webley/Peter Zackariasson (eds.), The Playful Undead and Video Games Critical Analyses of Zombies and Gameplay, London: Routledge, pp. 197-215.

Pfister, Eugen (2020a): „Political Communication in Digital Horror Games.“ In: Horror-Game-Politics (http://hgp.hypotheses.org/1062).

Pfister, Eugen (2020b): „Zombies Ate Democracy: The myth of a systemic political failure in video games." In: Stephen Webley/Peter Zackariasson (eds.), The Playful Undead and Video Games Critical Analyses of Zombies and Gameplay, London: Routledge, pp. 216-231.

Pfister, Eugen (2018): „Der Politische Mythos als diskursive Aussage im digitalen Spiel. Ein Beitrag aus der Perspektive der Politikgeschichte.“ In: Thorsten Junge/Claudia Schumacher (eds.), Digitale Spiele im Diskurs, Hagen: Fernuni Hagen (http://www.medien-im-diskurs.de). 
Pinchbeck, Dan (2009): "Shock, Horror: First-Person Gaming, Horror and the Art of Ludic Manipulation.“ In: Bernard Perron (ed.), Horror Video Game, Jefferson: McFarland, pp. 79-94.

Rath, Gudrun (2014): „Zombi/e/s. Zur Einleitung.“ In: Gudrun Rath (ed.), Zombies, Bielefeld: Transcript, pp. 11-20.

Santilli, Paul (2007): "Culture, Evil and Horror.” In: American Journal of Economics and Sociology 66/1, pp. 173-194.

Taylor, Laurie (2009): “Gothic Bloodlines in Survival Horror Gaming.” In: Bernard Perron (ed.), Horror Video Game, Jefferson: McFarland, pp. 46-61.

Totten, Christopher (2012): "Building a Better Zombie.” In: Gamasutra (https:// www.gamasutra.com/view/feature/173144/building_a_better_zombie.php).

Sarasin, Philipp (2003): Geschichtswissenschaft und Diskursanalyse, Frankfurt am Main: Suhrkamp.

Schrape, Niklas (2012): Die Rhetorik von Computerspielen. Wie politische Spiele überzeugen, Frankfurt am Main: Campus.

Suter, Beat (2018): "Rules of Play as a Framework for the "Magic Circle'." In: Beat Suter/Mela Kocher/René Bauer (eds.), Games and Rules. Game Mechanics for the Magic Circle, Bielefeld: Transcript, pp. 19-34.

Therrien, Carl (2009): "Games of Fear: A Multi-Faceted Historical Account of the Horror Genre in Video Games." In: Bernard Perron (ed.), Horror Video Game, Jefferson: McFarland, pp. 26-45.

Webster, Andrew (2019): “Ubisoft keeps pretending its political games don't have politics in them." In: The Verge (https://www.theverge.com/2019/5/9/ 18563382/ubisoft-ghost-recon-breakpoint-politics).

\section{Games}

Alone in the Dark, Infogrames, Infogrames, 1992.

Atom Zombie Smasher, Blendo Games 2011.

Days Gone, SIE Bend Studio, Sony, 2019.

DayZ, Bohemia Interactive, Bohemia Interactive, 2018.

Dead Island, Techland, Deep Silver, 2011.

Dead Rising, Capcom, Capcom, 2006.

Dying Light, Techland, Warner Bros, 2015.

Left4Dead, Valve South, Valve, 2008.

Mass Effect, BioWare, Microsoft 2007.

Overkill's The Walking Dead, Overkill Software, Starbreeze Publishing, 2018.

Pillars of Eternity, Obsidian Entertainment, Paradox Interactive, 2015.

State of Decay, Undead Labs, Microsoft Studios, 2013. 
State of Decay 2, Undead Labs, Microsoft Studios, 2018.

The Last of Us, Naughty Dog, Sony, 2013.

The Last of Us: Part II, Naughty Dog, Sony, 2020.

The Organ Trail, The Men Who Wear Many Hats, The Men Who Wear Many Hats, 2015.

The Walking Dead, Telltale Games, Telltale Games, 2012-2019.

The Witcher 3: Wild Hunt, CD project Red, Bandai Namco Games, 2015.

They Are Billions, Numantian Games, Numantian Games, 2019. 
